\title{
Modification Technology Research of Involute Helical Gear
}

\author{
Hongbin Yang, Xun Fu, Houyun Dong \\ School of Mechatronics Engineering, Henan University of Science \&Technology, Luoyang 471003, \\ China
}

Keywords: Gear modification, Modification processing, Modification effect evaluation.

\begin{abstract}
Gear modification is a key technology of reducing vibration and noise, improving the stability of gear transmission system. In this paper the theory of modification and processing technology is discussed, and the evaluation methods of modification effect have been summarized based on the existing researches. This paper provides references of reasonable gear modification for designers.
\end{abstract}

\section{Introduction}

The gears produce larger vibration, noise and speed fluctuation in gear meshing due to the influence of the manufacturing, installation error, thermal elastic deformation of gear and the elastic deformation of shaft, which reduce bearing capacity and the life of gear. Improving transmission performance only by improving fabrication and installation accuracy of gear will increase unnecessary costs, and the effect is limited. But gear modification can reduce the effect of above problems [1]. Based on the principle of gear modification, the commonly used helical gear modification and the evaluation methods in domestic and overseas are comprehensively summarized and discussed in this paper, which has significant engineering practical value.

\section{Theory of gear modification}

Gear modification includes profile modification and axial modification. Profile modification refers to remove a part of material from the tooth surface along the depth direction, so as to change the shape of tooth profile and reduce the meshing impact which is caused by elastic deformation of gear. The course is shown in Fig.1a. Axial modification refers to the modification along tooth width direction, which can compensate for gear tooth deviation caused by torsional bending elastic deformation of shaft and tooth, eliminating of partial load, increasing the bearing capacity and reliability of the gear. Tooth surface load distribution of torsional bending deformation of gear is shown in Fig.1b[1].

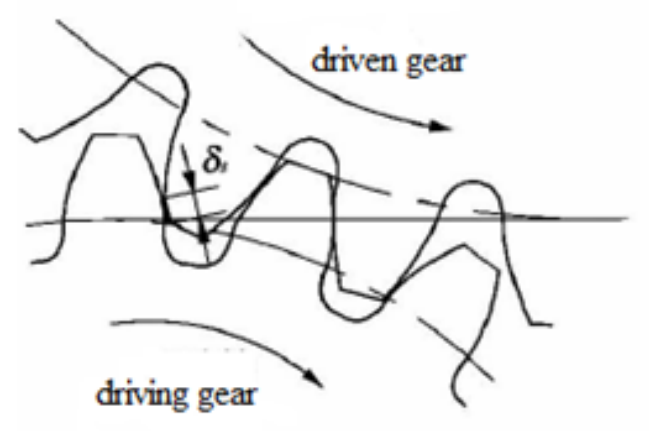

(a) The meshing impact caused by interference of tooth

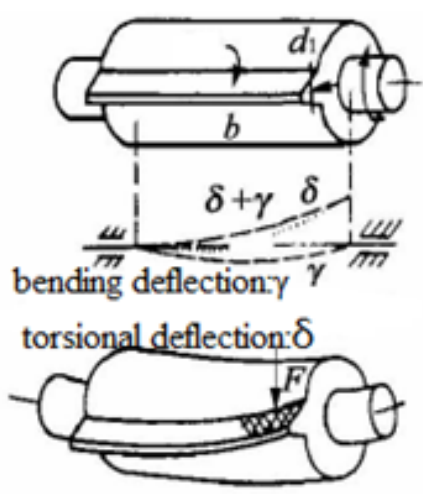

(b) Tooth surface load distribution of torsional bending deformation of gear

\subsection{Profile modification}

Fig. 1:Theory of gear modification

Profile modification has three forms: addendum modification, dedendum modification, whole 
profile modification.

Two modification methods are as follow: (1) addendum modification can be done on the two meshing gears; (2) whole profile modification can be done on one of the two meshing gears. Generally, dedendum modification does not be used alone in case of reducing the tooth bending strength. From processing manufaturability consideration, whole profile modification is usually done on small gear. Basic parameters of the profile modification include: modification amount,modification length and modification curve .

Modification amount is equal to elastic deformation of two meshing gear teeth at the meshing alternating point of single and double teeth. At present, the accurate calculation method of the elastic deformation of gear tooth are mainly based on the material mechanics method [3-4]of variable cross-section cantilever beam model[2] and finite element method[5-6].

Because many factors affect modification amount, the precise calculation of modification amount is relatively complex.In practical application ,the simplified empirical formulas are used in involute helical gear modification. The formulas are shown as Table 1.

Table 1:The formulas of helical gear profile modification $\left(\mathrm{W}_{\mathrm{t}}\right.$ is the load of unit tooth width, $\mathrm{N} / \mathrm{mm}$ )

\begin{tabular}{|c|c|c|}
\hline & $\begin{array}{l}\text { Starting meshing } \\
\text { point }\end{array}$ & End meshing point \\
\hline $\begin{array}{l}\text { The } \\
\text { recommended } \\
\text { formulas in } \\
\text { GB } \\
\text { (Unit: um) }\end{array}$ & $\begin{array}{l}\Delta_{1 \mu}=5+0.04 W_{\mathrm{t}} \\
\Delta_{1 o}=13+0.04 W_{\mathrm{t}}\end{array}$ & $\begin{array}{l}\Delta_{2 \mu}=0.04 W_{\mathrm{t}} \\
\Delta_{2 o}=5+0.04 W_{\mathrm{t}}\end{array}$ \\
\hline $\begin{array}{l}\text { The } \\
\text { recommended } \\
\text { formulas in }\end{array}$ & $\begin{array}{l}\Delta_{1 \mu}=0.00508 \\
+0.0406 W_{t} \times 10^{-3}\end{array}$ & $\Delta_{2 \mu}=0.0406 W_{t} \times 10^{-3}$ \\
\hline $\begin{array}{l}\text { MAAG (Unit: } \\
\text { mm) }\end{array}$ & $\begin{array}{l}\Delta_{1 o}=0.0127 \\
+0.0406 W_{t} \times 10^{-3}\end{array}$ & $\begin{array}{l}\Delta_{2 o}=0.00762 \\
+0.0406 W_{\mathrm{t}} \times 10^{-3}\end{array}$ \\
\hline $\begin{array}{l}\text { The } \\
\text { recommended } \\
\text { formulas in } \\
\text { RENK (Unit: } \\
\text { mm) }\end{array}$ & $\begin{array}{l}\Delta_{1 \mu}=4 W_{\mathrm{t}} \times 10^{-5} \\
\Delta_{1 o}=0.008 \\
+4 W_{t} \times 10^{-5}\end{array}$ & $\begin{array}{l}\Delta_{2 \mu}=0.005+4 W_{t} \times 10^{-5} \\
\Delta_{2 o}=0.013+4 W_{t} \times 10^{-5}\end{array}$ \\
\hline
\end{tabular}

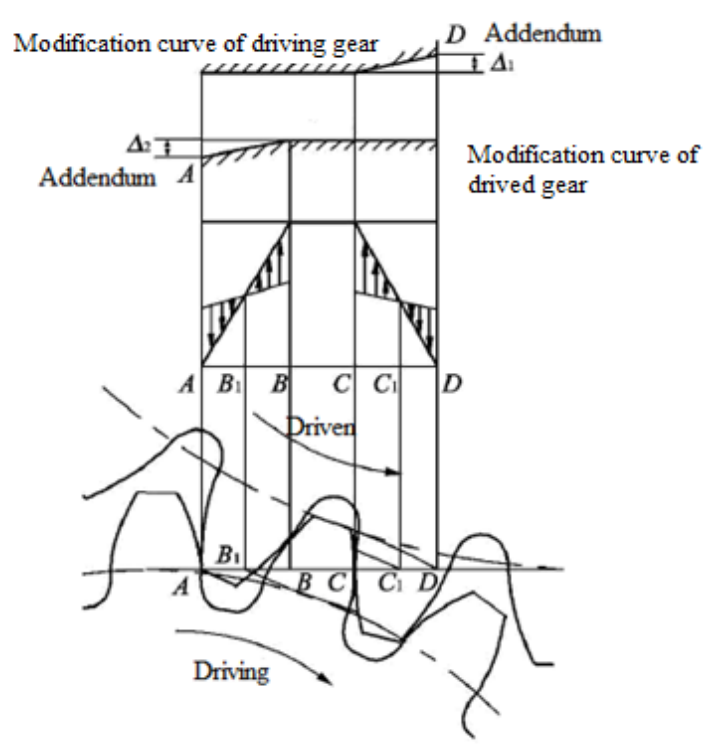

Fig. 2:Profile modification

Gear modification length is divided into short modification, and long modification[6]. As shown 
in figure 2, two gears mesh into at point $\mathrm{A}$ and mesh out at point $\mathrm{D}$. Meshing line $\mathrm{AD}$ stands for a meshing cycle. $\mathrm{AB}, \mathrm{CD}$ segments are double toothed meshing zone, $\mathrm{BC}$ segment is single toothed meshing zone. Long modification starts at the single and double teeth meshing alternating points $\mathrm{B}, \mathrm{C}$, whose modification scope is $\mathrm{AB}$ and $\mathrm{CD}$ segments. Short modification starts at the midpoints $\mathrm{B}_{1}$, $\mathrm{C}_{1}$ of double teeth meshing zone, whose modification scope is $\mathrm{AB}_{1}$ and $\mathrm{C}_{1} \mathrm{D}$ segments. Long modification can make the gear load transit smoothly at the single and double teeth meshing alternating points, which is commonly used in profile modification of gears with large tooth width and spiral angle of single and double helical gear tooth. Short modification is generally used in spur and conventional helical gears to overcome the gear contact ratio decrease after modification.

The modification curve is generally expressed in the form of power function as

$$
e=e_{k}\left(\frac{x}{l}\right)^{b}
$$

$x$ is relative coordinate at meshing position; ${ }^{l}$ is the modification length; $e$ is the modification amount; $e_{k}$ is the largest modification amount; the power exponent b values from 1.0 to 2.0 in general. When $b=1.0$, the modification curve is straight line which can't smoothly connect with tooth profile and reduce the impact. When $\mathrm{b}=1.35$, the transmission error is approximate to straight line which transmits relatively smoothly. When $b=2$, the modification curve is parabola which can smoothly connect with tooth profile and reduce the meshing impact. Walker[7] recommended $b=1.5$. Runfang $\mathrm{Li}$ [8] recommended $b=2$ in the light load condition; $b=1.35$ in the rest condition. It is better to use $b=2$ in the transmission system which has larger changes in load so as to ensure the contact ratio is greater than 1 and avoid or reduce the meshing impact.

\subsection{Axial modification}

The main purpose of axial modification is to remove the influence of torsional bending elastic deformation of shaft to gear meshing and make gear obtain a relatively uniform distribution of axial load. Researches show [9] that axial modification can reduce the peak value of the tooth root bending stress and tooth surface contact stress, change the peak value position from the edge to the central tooth and improve the bearing capacity of tooth surface. But excessive axial modification can lead to larger tooth surface contact stress which cause pitting on tooth surface. Gears with small width diameter ratio only need to blunt down the gear face edge without axial modification. Gears with medium and large width diameter ratio need axial modification to compensate manufacturing and installation error and torsional bending elastic deformation of shaft. As shown in Fig. 3, axial modification has three forms including crowning, helix angle trimming and end relief.

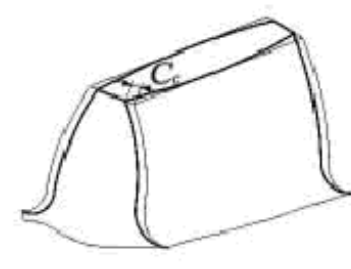

(a) crowning

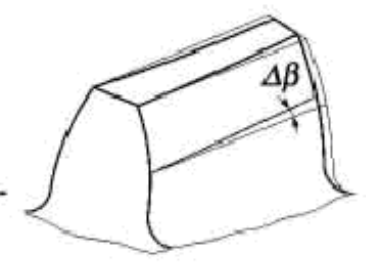

(b)helix angle trimming

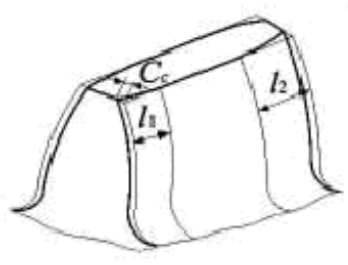

(c) end relief

Fig. 4:Axial modification

(1) Crowning: At present, there are two main methods to calculate drum amount. One is directly giving the reference value based on experience, the other is calculating based on the theoretical formulas. With the development of the finite element technology, some scholars put forward adopting finite element method to calculate drum amount which obtained a certain modification effect.

In the ISO standard, drum amount $\Delta$ of general gear is $10 \mu \mathrm{m} \leq \Delta \leq 40 \mu \mathrm{m}$ which need to plus 5 $\mu \mathrm{m}$ manufacturing deviation. Drum amount $\Delta$ of high speed gears with high precision and reliability is $10 \mu \mathrm{m} \leq \Delta \leq 25 \mu \mathrm{m}$ which need to plus $5^{\mu \mathrm{m}}$ manufacturing deviation[1].

Considering the meshing tooth alignment error of gears, the recommended formula in ISO can be written as follow: 


$$
\Delta=0.5 F_{\beta y}
$$

Considering original meshing tooth alignment contact error and contact deformation, Lemin Song [9]put forward formula written as:

$$
\Delta=0.5 F_{\beta y}+\frac{F_{m}}{C b}
$$

About the location of the drum center, general data recommended to choose the midpoint of tooth width, but the effect is not the best. Lemin Song recommended calculating formulas as :

$$
\begin{gathered}
b_{c}=2 b_{c l}=\sqrt{\frac{8 F_{m} b}{C F_{\beta y}}} \quad\left(b_{c l} \leq b\right) \\
b_{c}=2 b_{c l}=b+\frac{2 F_{m}}{C F_{\beta y}} \quad\left(b_{c l} \geq b\right)
\end{gathered}
$$

$F_{m}$ is the peripheral force uniformly around the pitch circle of tooth width. b is tooth width. ${ }^{F_{\beta y}}$ is meshing tooth alignment error. ${ }^{b l}$ is the contact width. $\mathrm{C}$ is meshing comprehensive stiffness.

(2) Helix angle trimming [10]: The main function of helix angle trimming is eliminating helix angle error including overall helix angle error and local helix angle error. Overall helix angle error is caused by helix angle manufacturing error , skew degree and parallel degree error of the bearing hole, concentricity error of bearing inner and outside diameter and parallel degree error of shaft center line etc. Local helix angle error is caused by torsional bending elastic deformation of shaft and thermal deformation due to uneven temperature of tooth alignment at different parts along the tooth width. The vector synthesis of the above two kinds of error is all condition helix angle error, whose mirror symmetry curve is the ideal helix angle modification curve.

The key of helix angle trimming is determining the modification amount. The process of calculating the optimal modification amount is actually an optimization problem. Generally, the optimal amount of helix angle trimming is obtained by establishing accurate finite element model of gear pair and analyzing the load distribution in the process of gear meshing.

(3) End relief[1]: The calculating formulas of end relief amount $\Delta$ are as follow:

$\Delta=f_{s h}+1.5 f_{H \beta}+(5 \sim 10) \mu m$

$\Delta=0.5\left(f_{\text {sh }}+1.5 f_{H \beta}\right)+(5 \sim 10) \mu m$

(tempered gears) (6)

(surface hardening and nitriding gears) (7)

For high speed gears with high precision and reliability, the end relief amount is $60 \% \sim 70 \%$ of the above value.

\section{Modification process of the gear}

There are mainly three modification processing methods: 1) using the modified cutting tool ; 2) using grinding machine; 3) using electrochemical machining process.

(1) Using the modified cutting tool realizes gear modification. Naishi Cheng[11] designed the hob and realized gear modification through gear hobbing according to the relationship he put forward between modification height, modification amount and starting modification point of tool, the modification arc radius based on gear machining theory.

(2) Using grinding machine realizes gear modification.There are two patterns of generating method in the profile modification of gear. One is that realizing tooth profile modification by adjusting the ratio of generating hanging wheels under constant grinding angle of grinding wheel. The other kind is that using copying attachment to dress grinding wheel into the tooth space shape of benchmark rack of modification gear. Axial modification is realized by using special designed modification templates to control the grinding wheel to make an additional movement along the axis of the grinding wheel in the scheduled time.

Forming grinding is realized by using dressing mechanism to dress the cross section of grinding wheel into the same shape with the tooth shape of modification gear. It adopts single-tooth indexing at work. This process can achieve the grinding of tooth profile and transition curve of tooth root, 
which also has the characteristics of high tooth shape precision, grinding unlimited number of teeth, simple operation and reliable running etc.

(3) Using electrochemical machining process realizes gear modification[12]. In electrochemical machining, the processed parts are placed as anode in the electrolyte, then metal of parts surface is removed through anodic dissolution after passing the DC. The main principle of electrochemical machining is based on the anodic dissolution of electrolytic process. Compared with other mechanical modification process, this method has high processing efficiency, high quality and a certain popularization value because of no hardness limitation of gear tooth, no chip and dust.

\section{The evaluation of modification effect}

According to the requirements of the design, modification effect is evaluated from the following three aspects.

\subsection{Vibration and noise measurement}

Decreasing vibration and noise is the main target of modification. So the measurement of vibration and noise of before and after the modification of gear system is an important index to examine modification effect. Generally precision sound level meter can be used to collect noise of gear and acceleration transducer can be used to measure vibration of gear. ZhaoBo Huo[13]tested vibration and noise of gears with different tooth profile modification parameters through this method and studied the influence of modification parameters on the vibration and noise. The test results showed that the optimal modification can significantly reduce the vibration and noise of gear, but the excessive modification amount can increase the vibration and noise of gear.

\subsection{Observation of meshing condition}

Modification can improve the gear contact state, so observing tooth surface contact moulage can evaluate the modification effect. The operating process is painting dilute red lead powder on tooth surface, running gear transmission device be tested under working load after the red lead powder dry completely. Observe tooth surface contact moulage after dozens of minutes to judge whether the moulage meets the design requirements. Zongde Fang [14] made contact analysis of modified gear through this way. The test results showed that contact moulage of modified gear distributed evenly on tooth surface, and partial load was improved significantly. This test method is simple and widely used in the production practice.

\subsection{Transmission error measurement}

Transmission error is equal to the displacement difference of base circle between driving gear and driven gear, which is an important index for measuring gear transmission accuracy. Zongde Fang[15] got the relatively flat acceleration waveform between two helical gears with acceleration sensor on the gear dynamic test bench. Then by carrying the fast Fourier transformation on the acceleration waveform, he got relative displacement spectrum of the loaded gear pair in the frequency domain. Finally through Fourier inverse transformation, he got the time series of relative displacement of gear pair under test load and the transmission error of gears. Above study showed that reasonable modification can significantly reduce the transmission error of gear pair.

\section{Conclusion}

(1) Practice showed that reasonable gear modification can improve gear contact state, reduce vibration and noise, improve the bearing capacity, prolong service life. But unreasonable modification amount is counterproductive.

(2) In order to obtain better modification effect, designers should choose reasonable modification method according to the actual working condition.

(3) Designers should choose the modification effect evaluation method according to the main purpose of modification, and should not choose blindly in case of causing unnecessary waste. 


\section{References}

[1] Gear Guide Editorial Board. Gear Guide. Beijing: China Machine Press, pp. 143-147,2000.

[2] The Japan Society of Mechanical Engineers. Design Information of Gear Strength. Ruzhen Li, Qinghui Zhao, Translation. Beijing: China Machine Press, pp. 131-139,1984.

[3] Terauchi Y, Nagamua K. Study on Deflection of Spur Gear Teeth. 1st Report. Bulletin of JSME, 23(184), pp. 1682-1688,1980.

[4] Terauchi Y, Nagamua K. Study on Deflection of Spur Gear Teeth. 2nd Report. Bulletin of JSME, 24(188), pp. 447-452,1980.

[5] Jianguo Sun,Tengjiao Lin,Runfang Li, etc. Dynamic Contact Finite Element Analysis and Modification of Involute Gear.Journal of Mechanical Transmission, 32(2), pp. 8-58,2008.

[6] Zhenguo Shang, Hua Wang. Finite element Analysis on Profile Modification in Speed Increase Gearbox for the Wind driven Generator. Journal of Mechanical Transmission, 33(4), pp. 68-70,2009.

[7] Walker H. Gear Tooth Defection and Profile Modification (Part1\&Part2). The Engineer, 166(4318), pp. 409-412, (4319), pp. 434-436,1938.

[8] Runfang Li. Stiffness Analysis of Gear Transmission and the Modification Method. Chongqing: Chongqing university Press, pp. 153-160, 247-248,1998.

[9] Lemin Song. Profile and Strength of Gear Teeth. Beijing: National Defence Industry Press, pp. 109-118,2000.

[10] Ming Li. Research on Longitudinal Correction of Helical Gear in Gearbox for Wind Turbine Generator. Dalian University of Technology, pp. 17-20,2008.

[11] Naishi cheng, Wen Liu, Jingzi Zhu, etc. Profile Modification of Involute Spur Gear Tooth and Design of Modification Hob.Metallurgical equipment, pp. 30-36,1981.

[12]Guibing Pang. Pulse Electrochemical and Mechanical Gear Finishing and Modification Processing Technology Research. Dalian: Dalian University of Technology, pp. 21-42,2005.

[13]Zhaopuo Huo, delin Xu, zhenzhong Xu. Experimental Research on Vibration Reduction Profile Modification of Helical Gears. Journal of Engineering for Thermal Energy and Power, pp. 9-11,1996.

[14] Zongde Fang, Ning Zhao. Calculation and Experiment on the three Dimensional Modification of Cylindrical Gears. Manufacturing Technology \& Machine Tool,pp. 24-26,1995.

[15] Zongde Fang, Yongcai Zhang, Tiancun Lin. Experimental Research of the Helical Gear Tooth Profile Modification. Journal of Mechanical Transmission, 16(4), pp. 27-30.1992. 